Table 1

Means and Standard Deviations of the Number of Trials to Criterion on the Acquisition Task

\begin{tabular}{|c|c|c|c|c|c|}
\hline \multirow{2}{*}{$\begin{array}{c}\text { Strategy } \\
\text { Style }\end{array}$} & & \multicolumn{3}{|c|}{ Treatment Condition } & \multirow{2}{*}{$\begin{array}{l}\text { Style } \\
(\mathrm{N}=54)\end{array}$} \\
\hline & & Complex & Simple & Control & \\
\hline High Producers & $\begin{array}{l}\bar{X} \\
S D\end{array}$ & $\begin{array}{l}5.28 \\
1.70\end{array}$ & $\begin{array}{l}7.56 \\
1.65\end{array}$ & $\begin{array}{l}6.33 \\
1.93\end{array}$ & $\begin{array}{l}6.39 \\
1.41\end{array}$ \\
\hline Variable Producers & $\begin{array}{l}\bar{X} \\
\text { SD }\end{array}$ & $\begin{array}{r}5.61 \\
.98\end{array}$ & $\begin{array}{l}7.11 \\
1.84\end{array}$ & $\begin{array}{l}7.00 \\
1.68\end{array}$ & $\begin{array}{l}6.57 \\
1.67\end{array}$ \\
\hline Low Producers & $\begin{array}{l}\overline{\mathrm{X}} \\
\mathrm{SD}\end{array}$ & $\begin{array}{l}6.17 \\
1.20\end{array}$ & $\begin{array}{l}8.72 \\
1.56\end{array}$ & $\begin{array}{r}7.17 \\
.88\end{array}$ & $\begin{array}{l}7.35 \\
1.62\end{array}$ \\
\hline Treatment $(\mathrm{N}=54)$ & $\begin{array}{l}\bar{X} \\
\text { SD }\end{array}$ & $\begin{array}{l}5.68 \\
1.36\end{array}$ & $\begin{array}{l}7.80 \\
1.15\end{array}$ & $\begin{array}{l}6.85 \\
1.57\end{array}$ & \\
\hline
\end{tabular}

condition. Moreover, high-level strategy producers reached criterion on the acquisition task significantly faster than did Ss producing low-level strategies.

The relationship between the number of trials to criterion and a strategy score based on the strategies Ss reported after acquisition was examined. For all $162 \mathrm{Ss}$, the resulting correlation was -.66 $(\mathrm{p}<.01)$, indicating that $\mathrm{Ss}$ with high strategy scores required fewer trials to reach criterion.

The median strategy scores for the high, variable, and low strategy producers assigned to the control treatment were 75 , 56 , and 52.5, respectively. Individual comparisons by means of the Mann-Whitney $U$ test revealed that the high strategy producers were significantly different from both the variable and low producers $(p<.01)$, but the variable and low strategy groups were not different from each other.

The results indicate that the complex E-supplied mediation treatment was the most facilitating. The control condition resulted in a significantly faster learning rate than did the simple mediation treatment condition. It appears that the introduction of less effective E-supplied mediators resulted in a tendency for Ss to abandon more effective associative strategies.

The mediational style of the learner proved to be an important variable in accounting for individual differences in rate of learning. It was demonstrated that Ss who were independently classified as high associative strategy producers (complex mediational style) learned at faster rates than did Ss identified as low-strategy producers (simple mediational style). These differences were obtained despite the fact that analyses of IQ and achievement scores for the nine subgroups revealed no significant differences among them. Mediational style is apparently not directly related to $I Q$ and school achievement, yet it does differentiate between fast and slow learners. Moreover, differences on this dimension between high-strategy producers and low and

\section{ROBERT S. DAVIDSON, JR., V.A Hospital, Miami, Fla. 33125}

Five undergraduate psychology majors and one high school student were trained to vocalize for point reinforcement. Once they did this regularly, they were trained to verbalize freely for points on fixed-interval schedules. Each of the $S_{s}$ spoke at high rates with rare pauses until an $S^{D}$ for reinforcement was delivered contingent on responses in the latter portion of each interval. This procedure shaped up regular postreinforcement pauses and bursts of responses at high rate prior to each reinforcement within few sessions.

Several studies have reported difficulties in generating human behavior under the control of fixed-interval schedules of reinforcement. A large body of data collected with animals of many species, ranging from rats and pigeons (Ferster \& Skinner, 1957) to monkeys (Fry et al, 1960), demonstrates that the expected behavior under fixed-interval schedules of reinforcement consists of pausing after each reinforcement and gradual acceleration in rate until the delivery of the next reinforcement. This topography or storage devices than do simpler mediators Although determination of S's mediational style may permit some accuracy in predicting efficient performance, the complexity of the E-supplied mediator remains the major variable in the effective facilitation of PA learning.

\section{REFERENCES}

CIEUTAT, V. J. Association indices for 446 randomly selected English monosyllables, bisyllables and trisyllables. Journal of Verbal Learning \& Verbal Behavior, 1963, 2, 176-185. DAVIDSON, R. E. Mediation and ability in paired-associate learning. Journal of Educational Psychology, 1964, 55, 352-356.

variable producers were found to remain consistent for nonaided Ss before and after acquisition.

The results revealed no interaction between mediational style and type of mediation treatment. Approximation of the mediation treatment to the mediational style of the learner proved not to be a factor in facilitating learning. Complex mediators, whether self-generated or E-supplied, apparently serve as better
JENSEN, A. R., \& ROHWER, W. D. Verbal mediation in paired-associate and serial learning. Journal of Verbal Learning \& Verbal Behavior, 1963, 2, 346-352.

MARTIN, C. J., BOERSMA, F. J., \& COX, D. L. A classification of associative strategies in paired-associate leaming. Psychonomic Science, 1965, 3, 455-456.

NOBLE, C. E. An analysis of meaning. Psychological Review, 1952, 59, 421-430.

SPIKER, C. C. Associative transfer in verbal paired-associate learning. Child Development, $1960,31,73-87$.

\title{
Rapid shaping of fixed-interval verbal behavior
}

pattern of response has been called "scalloping" (Ferster \& Skinner, 1957).

Reports of scalloping behavior in humans have been rare, although patterns of high and low rates of response on FI schedules have been found (Blair, 1958; Lippman \& Meyer, 1967; Weiner, 1962, 1964, 1969). Lippman \& Meyer (1967), Blair (1958), and Weiner (1962) found high rates of response with very little pausing without specific manipulation. Lippman and Meyer used instructions regarding the contingency, while Weiner (1969) used histories of response cost and differential reinforcement of low rates (DRL) to shape pausing after reinforcement.

The current study was an attempt to develop a quicker method of generating scalloping behavior on fixed interval schedules of reinforcement. In addition, the response manipulated was free operant speech.

\section{SUBJECTS}

Five undergraduate psychology majors and one high school student volunteered to serve as Ss for an experiment in learning. They were told very little prior to the first session, except that they could earn money by participating. Each S was actually paid 


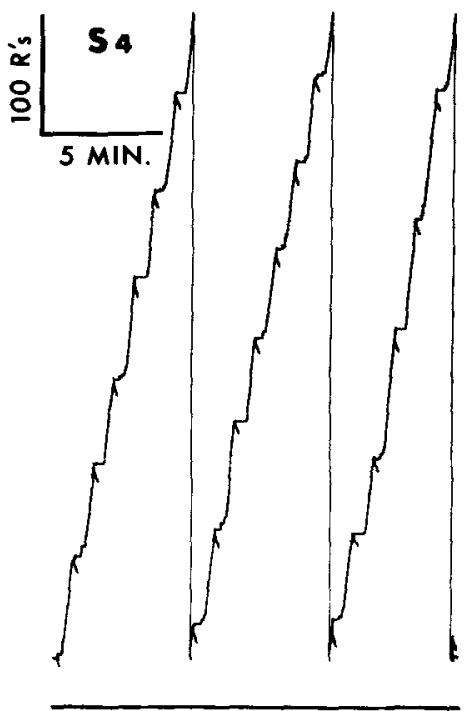

at the rate of $\$ 1.50 / \mathrm{h}$, contingent on regular attendance. Absenteeism was not a problem under these conditions.

\section{APPARATUS}

The Ss were run in an $8 \times 8 \mathrm{ft}$ cubicle, in which a chair enabled them to sit before a table containing a panel with an electrical counter between a red and white light. A microphone next to the panel allowed recording, monitoring, and programming of all vocal behavior. The microphone was connected to a noise-operated relay (Hunter 320S) that delivered impulses corresponding to sounds of $S$ to cumulative recorders, counters, and relay-operated programming equipment.

All monitoring and programming equipment was housed in a room adjacent to the experimental cubicle. The two rooms were connected by a one-way-vision mirror that allowed $\mathrm{E}$ visual contact with $\mathrm{S}$ at all times.

\section{PROCEDURE}

Each $S$ was ushered into the experimental cubicle, shown to a seat and presented with a set of printed instructions that told him he was to earn points to be registered on the counter in a way that he would have to learn.

Each $S$ was informed that the sessions would be about $20 \mathrm{~min}$ long and that he might be needed for 20 or more such sessions.

In the first sessions, $S$ received a point and a response-contingent flash of white light for each vocalization. Under these conditions, one $S$ coughed, one whistled, one said, "Testing, 1, 2, 3, 4," and a few said, "I wonder if I'm supposed to talk." After the initial vocalizations were followed by lights and points, they tended to be repeated. When they reached some rate of response, lights and points were withheld for a time until a new response

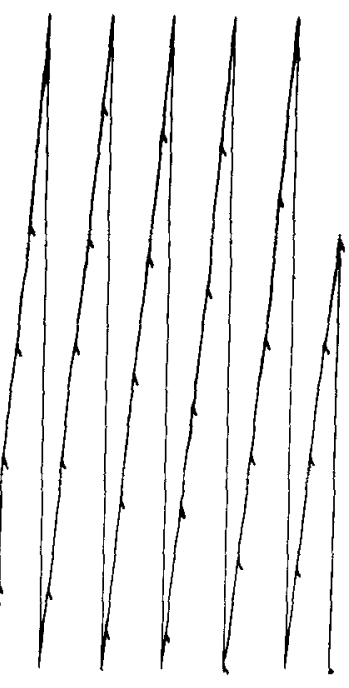

Fig. 1. Cumulative records of S4 responding verbally on FI 50 schedule of point reinforcement before (right) and after (left) rapid shaping procedure. Approximately 550 responses are accumulated prior to each automatic pen reset. Downward pips of the response pen indicate reinforcement. Note the lack of lengthy pauses and high response rate $(208 \mathrm{rpm})$ in the record on the right (10th session). Following shaping, responding was maintained at high rate prior to each reinforcement, but pauses occurred with high probability following each reinforcement, reducing overall rpm to 94 (14th session).

\section{RESULTS AND DISCUSSION}

Under the conditions just described, most Ss showed the development of reliable pausing after each reinforcement and responding at high rates prior to each reinforcement. Behavior typical of each of the Ss is depicted in the left portion of Fig. 1. Changes from behavior as seen in the right panel to that in the left required one to five sessions for these six Ss.

This procedure is suggested, then, as one approach to the rapid shaping of fixed-interval behavior that does not depend upon the direct instruction to $S$ of the contingency involved (as was done by Lippman \& Meyer, 1967) and that should be more expedient in saving time over that usually required to shape animals to such schedules (frequently a month or more). This shaping procedure should also save time and eliminate the necessity of building in a different history of reinforcement, as was done by Weiner $(1962,1964,1969)$.

\section{REFERENCES}

BLAIR, W. C. Measurement of observing in human monitoring. Science, 1958, 128, 255-256.

FERSTER, C. B., \& SKINNER, B. F. Schedules of reinforcement. New York: Appleton-Century-Crofts, 1957.

FRY, W., KELLEHER, R. T., \& COOK, L. A mathematical index of performance on fixed-interval schedules of reinforcement. Journal of the Experimental Analysis of Behavior, 1960, 3, 193-199.

LIPPM AN, L. G., \& MEYER, M. E. Fixed-interval performance as related to instructions and to subjects' verbalizations of the contingency. Psychonomic Science, 1967, 8, 135-136.

WEINER, H. Some effects of response cost upon human operant behavior. Journal of the Experimental Analysis of Behavior, 1962, 5, 201-208.

WEINER, H. Conditioning history and human fixed-interval performance. Journal of the Experimental Analysis of Behavior, 1964, 7, 333-335.

WEINER, H. Controlling human fixed-interval performance. Journal of the Experimental Analysis of Behavior, 1969, 12, 349-373. 